\title{
Stress and Aging Effects on the Transformation Characteristics in Au-Cd Alloys
}

\author{
T.R. Finlayson ${ }^{1}$, G.L. Kelly ${ }^{1}$, T. Ersez ${ }^{2}$ and T.F. Smith ${ }^{3}$ \\ ${ }^{1}$ Department of Physics, Monash University, Clayton, Vic. 3168, Australia \\ ${ }^{2}$ Neutron Scattering Group, ANSTO, PMB 1, Menai, NSW 2234, Australia \\ ${ }^{3}$ Vice-Chancellor's Department, La Trobe University, Bundoora, Vic. 3083, Australia
}

Keywords: Gold-Cadmium Alloys, Aging Effect, Applied Stress

\begin{abstract}
The effect of martensite aging in a $\mathrm{Au}-49.5 \% \mathrm{Cd}$ single crystal has been studied using a pushrod dilatometer with various applied stresses. The reverse transformation temperatures, $A_{s}$ and $A_{f}$, are strongly influenced by the aging time and temperature. The $M_{s}$ and $M_{f}$ temperatures remain constant with aging time, temperature and applied stresses $(0-0.04 \mathrm{MPa})$. A critical aging time of approximately $2-3$ hours was found to exist for an alloy of this composition and appears to be dependent on the aging temperature.
\end{abstract}

\section{Introduction}

Au-Cd alloys of approximately equiatomic composition undergo martensitic phase transformations. Alloys with the compositions of approximately Au-49.5at.\%Cd alloys undergo a $\beta_{2}(\mathrm{~B} 2) \rightarrow \zeta_{2}^{\prime}$ (trigonal) phase transformation while Au-47.5at.\%Cd undergoes a $\beta_{2}$ (B2) $\rightarrow \gamma_{2}^{\prime}$ (orthorhombic) phase transformation. A number of studies have investigated the transformation-associated, shapememory effect and superelasticity $[1,2,3]$ and the $\zeta_{2}^{\prime}$ [4] and $\gamma_{2}^{\prime}$ crystal structures have been determined. In addition to producing the rubber-like behaviour in thermoelastic alloys such as Au49.5at\% $\%$ [3], Au-47.5at\% Cd, $\mathrm{CuZnAl}[5]$ and $\mathrm{AuCuZn}$ [6], aging in the martensitic state also increases the $A_{s}$ (reverse transformation start) and $A_{f}$ (reverse transformation finish) temperatures. This phenomenon is referred to as the aging effect. It is generally assumed that the aging effect and superelasticity have the same physical origin [1].

Two models for the martensitic aging effect have been discussed. The "boundary effect model" depends on the pinning of martensite plate boundaries $[7,8]$, while the "volume effect model" is related to the re-ordering of martensites $[9,10]$. In the first model, it is assumed that the martensite plate boundaries become less mobile with aging on account of pinning by, for example, vacancies and thus the $A_{8}$ temperature is expected to increase. In the second model, the free energy change of the martensite is considered to occur by shuffling, reordering or development of short-range ordering during aging.

Kuroiwa et al. [11] have reported that the critical aging time is dependent on the aging temperature, with this dependence becoming stronger as the aging temperature approaches $\mathrm{A}_{\mathrm{s}}$. They also report significant differences in the changes of the surface martensite patterns on heating samples aged at different times and temperatures. These changes were attributed to differences in transformation dynamics. 
In this study, the transformation temperatures of an $\mathrm{Au}-49.5 \mathrm{at} \% \mathrm{Cd}$ alloy were measured following various aging times for a constant applied stress. Also, the aging effect was investigated for various applied stresses.

\section{Experimental Procedure}

The single crystal was grown using the Bridgman method and was annealed at $530^{\circ} \mathrm{C}$ for 24 hours for homogenization before furnace cooling. The dimensions of the crystal were $38 \times 10 \times 2 \mathrm{~mm}^{3}$ and $\langle 100\rangle$ was the measuring direction, along the longest dimension of the specimen.

The transformation temperatures were determined by measuring strain as a function of temperature using an Adamel Lhomargy DI-24 alumina pushrod dilatometer. The measurement procedure first involved aging the sample for various periods at around $22^{\circ} \mathrm{C}$ in the martensite phase without an applied preload stress. Following aging, strain measurements were made as the sample was heated through the reverse transformation to $100^{\circ} \mathrm{C}\left(\mathrm{A}_{\mathrm{f}} \sim 58^{\circ} \mathrm{C}\right)$. In the parent state a stress was applied and strain measurements were then made as the sample was cooled to room temperature and as it was immediately heated to $100^{\circ} \mathrm{C}$ and cooled while keeping the same applied stress. The stresses ranged from 0 to $0.04 \mathrm{MPa}$.

All of the experiments were carried out on the same sample and it was assumed that the previous aging effect was completely annihilated by the subsequent reverse transformation [12].

\section{Results}

The strain versus temperature curves obtained for a sample loaded at $100^{\circ} \mathrm{C}$ with applied stresses ranging between 0 and $0.04 \mathrm{MPa}$ and then cooled (to $22^{\circ} \mathrm{C}$ ) followed by immediate heating (to $\left.100^{\circ} \mathrm{C}\right)$ and cooling to $\left(22^{\circ} \mathrm{C}\right)$ are presented in Fig. 1.

In Fig. 2, the $A_{s}$ and $A_{f}$ obtained for various aging times at $22^{\circ} \mathrm{C}$ with no preload stress are presented, together with the results of Kuroiwa et al. [11] (for aging at $20^{\circ} \mathrm{C}$ ) and Murakami et al. [12] for nominally the same composition alloy. Kuroiwa et al. [11] investigated the aging effect in a crystal of dimensions $\sim 2 \times 5 \times 5 \mathrm{~mm}^{3}$, as a function of aging time, by observing the surface martensite bands in an optical microscope equipped with a heating/cooling stage. Murakami et al. [12] used a "plate-like" specimen of dimensions $0.5 \times 0.5 \times 40 \mathrm{~mm}^{3}$ in their studies, employing the DSC technique. The overall trend of the reported transformation temperatures as functions of aging times is very similar for all three types of measurements in that there is a critical aging time, $t_{c}$, below which there is no aging effect on either $A_{s}$ or $A_{f}$. There is, however, a significant difference in the values of $A_{s}$ and $A_{f}$ reported for the three sets of measurements. Kuroiwa et al. [11] report $\mathrm{M}_{\mathrm{s}}=30^{\circ} \mathrm{C}$ for their sample, which agrees with $\mathrm{M}_{\mathrm{s}}=29^{\circ} \mathrm{C}$ that we obtained from the dilatometer measurements. Murakami et al. [12] do not record $\mathrm{M}_{\mathrm{s}}$ and $\mathrm{M}_{\mathrm{f}}$ for their sample.

\section{Discussion}

In Fig. 1, it can be seen that, as the applied stress is increased, $A_{s}$ and $A_{f}$ are reduced, decreasing the size of the hysteresis loop. The application of a small stress in the parent phase initially reduces the thermal energy required to depin variant boundaries, but as the stress increases, it significantly reduces the thermal energy required to complete the reverse transformation (Fig. 1). 


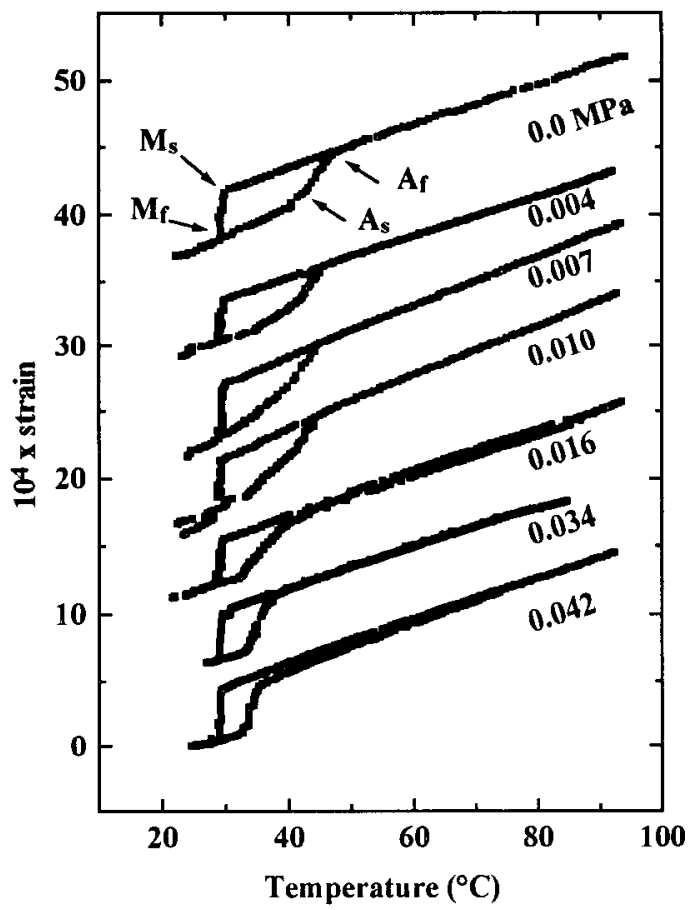

Figure 1: Strain versus temperature results obtained from a sequence of heating and cooling measurements (no aging) carried out at $22^{\circ} \mathrm{C}$ and with applied stresses ranging between 0.0 and $0.042 \mathrm{MPa}$ as indicated.

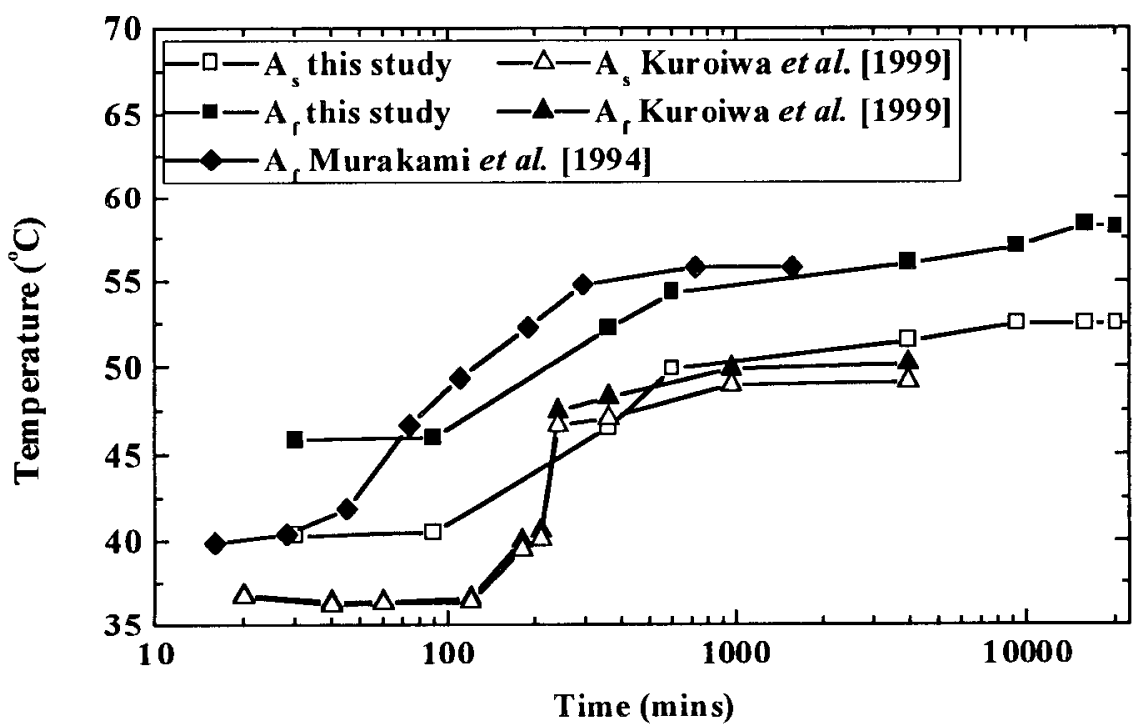

Figure 2: The $A_{s}$ and $A_{f}$ temperatures obtained for various aging times at $22^{\circ} \mathrm{C}$ with no preload stress. The results of Kuroiwa et al. [11] and Murakami et al. [12] for the same composition alloy are also included. 
The present measurements for the influence of aging time on the zero-applied-stress, temperaturestrain cycle, show an increase in temperature hysteresis but no change in the shape of the reversetransformation curve, resulting in the approximately constant difference, $A_{\mathbf{f}}-A_{s}$, for different aging times (Fig. 2). In interpreting this observation, we associate $A_{8}$ with the lowest thermal energy required to excite twin-boundary movement and $A_{f}-A_{s}$ with the range of values for this activation energy. It follows then, that aging, while increasing the lower limit for the thermal energy required to excite twin-boundary movement, does not change the spread of activation energies, in spite of any change that may occur in the transformation dynamics.

\section{Conclusion}

The results obtained in this investigation of an $\mathrm{Au}-49.5 \mathrm{at} \% \mathrm{Cd}$ alloy confirm the aging effect reported earlier with a critical aging time of 2-3 hours. It has also been found that the application of a small stress $(0-0.04 \mathrm{MPa})$ offsets the aging effect. It is concluded that the morphology of the martensite state and through this, the reverse transformation behaviour is influenced by the application of small stresses.

\section{Acknowledgements}

The authors wish to thank Professor T. Ohba of the School of Science and Engineering, Teikyo University, Japan and Professor K. Otsuka of the Department of Materials Science and Engineering, University of Tsukuba, Japan, for the kind loan of the Au-49.5at\%Cd single crystal. This work was supported by the Australian Research Council.

\section{References}

[1] K. Otsuka and C.M. Wayman, Review on the Deformation Behaviour of Materials, Vol. 2, ed. P. Feltman (1977), p. 83.

[2] K. Morii, S. Miyazaki and K. Otsuka, Proc. Int. Conf. on Martensitic Transformations, Monterey (1992), p. 1125.

[3] Y. Nakajima, S. Aoki, K. Otsuka and T. Ohba, Mater. Lett. 21 (1994), p. 271.

[4] T. Ohba, Y. Emura and K. Otsuka, Materials Trans. JIM 33 (1992), p. 29.

[5] G. Barcelo, R. Rapacioli and M. Ahlers, Scripta Metall. 12 (1978), p. 1069.

[6] S. Miura, S. Maeda and N. Nakanishi, Phil. Mag. 30 (1974), p. 565.

[7] J. Jansen, J. van Humbeeck, M. Chandrasekaran, N. Mwanba and L. Delaey, J. de Phys. 12 (1982), p. C4-715.

[8] A. Arab and M. Ahlers, J. de Phys. 12 (1982), p. C4-709.

[9] G. Scarsbrook, J. Cook and W. M. Stobbs, J. de Phys. 12 (1982), p. C4-703.

[10] T. Tadaki, H. Okazaki, Y. Nakata and K. Shimizu, Mater. Trans. JIM 31 (1990), p. 941.

[11] Y. Kuroiwa, T.R. Finlayson and T.F. Smith, J. Mater. Sci. Lett. (1999) in press.

[12] Y. Murakami, S. Morito, Y. Nakajima, K. Otsuka. T. Suzuki and T. Ohba, Mater. Lett. 21 (1994), p. 275.

\section{Corresponding Author}

Associate Professor T.R. Finlayson, E-mail: t.r.finlayson@sci.monash.edu.au, Fax: 61399053637 